\begin{tabular}{|c|c|c|}
\hline \multirow{3}{*}{$\begin{array}{r}\text { Case Reports in } \\
\text { Gastroenterology }\end{array}$} & \multirow{2}{*}{\multicolumn{2}{|c|}{ Case Rep Gastroenterol 2013;7:516-521 }} \\
\hline & & \\
\hline & $\begin{array}{l}\text { DOI: 10.1159/000357591 } \\
\text { Published online: December 13, } 2013\end{array}$ & $\begin{array}{l}\text { ○ } 2013 \text { S. Karger AG, Basel } \\
\text { 1662-0631/13/0073-0516 } \$ 38.00 / 0 \\
\text { www.karger.com/crg }\end{array}$ \\
\hline & \multicolumn{2}{|c|}{$\begin{array}{l}\text { This is an Open Access article licensed under the terms of the Creative Commons } \\
\text { Attribution-NonCommercial } 3.0 \text { Unported license (CC BY-NC) (www.karger.com/OA } \\
\text { license), applicable to the online version of the article only. Distribution permitted for non } \\
\text { commercial purposes only. }\end{array}$} \\
\hline
\end{tabular}

\title{
Laparoscopic Gastrectomy for Gastric Cancer with Peritoneal Dissemination after Induction Chemotherapy
}

\author{
Satoshi Tsutsumi Eiji Oki Satoshi Ida Koji Ando Yasue Kimura \\ Hiroshi Saeki Masaru Morita Tetsuya Kusumoto Tetsuo Ikeda \\ Yoshihiko Maehara
}

Department of Surgery and Science, Graduate School of Medical Sciences, Kyushu University, Fukuoka, Japan

\section{Key Words}

Gastric cancer · Peritoneal dissemination · Induction chemotherapy · Totally laparoscopic total gastrectomy

\begin{abstract}
Gastric cancer with peritoneal dissemination may be diagnosed as unresectable. More recently, as a result of progress in chemotherapy, some patients with peritoneal dissemination have exhibited extended survival. We report on our experience with three patients in whom induction chemotherapy allowed for totally laparoscopic total gastrectomy (TLTG). All three patients were diagnosed as having advanced gastric cancer with peritoneal dissemination using staging laparoscopy. As induction chemotherapy, S-1 combined with cisplatin was administered to two patients and trastuzumab plus capecitabine combined with cisplatin to one patient. TLTG was performed in all patients and there were no postoperative complications. Adjuvant chemotherapy was initiated within 3 weeks after surgery in all three patients. Laparoscopic gastrectomy undertaken after induction chemotherapy was found to be effective and safe; this treatment has the potential to achieve good treatment outcomes in patients with stage IV gastric cancer.

(C) 2013 S. Karger AG, Basel
\end{abstract}


Tsutsumi et al.: Laparoscopic Gastrectomy for Gastric Cancer with Peritoneal Dissemination after Induction Chemotherapy

\section{Introduction}

Gastric cancer is one of the leading causes of cancer death in East Asia and Eastern Europe, and it is the second most frequent cause of cancer-related death in Japan [1]. Although the incidence of gastric cancer in Japan has decreased in recent years, the prognosis of patients with advanced gastric cancer, especially those with peritoneal metastasis, remains poor. Usually, in such cases surgery is not the standard therapy, except for patients who require palliative surgery for related symptoms such as bleeding and obstruction. However, in recent years, as a consequence of progress in chemotherapy, some patients with peritoneal dissemination have achieved extended survival [2,3]. There have been some studies reporting that peritoneal dissemination disappeared after induction chemotherapy and that gastrectomy could be performed [4]. Here, we describe our experience with three cases of peritoneal dissemination, where the patients could be operated on using totally laparoscopic total gastrectomy (TLTG) after induction chemotherapy.

\section{Case Reports}

A total of three serial patients with primary gastric cancer and peritoneal dissemination or positive peritoneal lavage cytology were diagnosed from January 2012 to December 2012 at the Department of Surgery and Science (Department of Surgery II), Kyushu University Hospital in Japan. The staging of the tumors was based on the Union for International Cancer Control tumor, node, metastasis (TNM) classification system [5]. The pathological response of the primary tumor was assessed and divided into five categories of grades $0-3$, according to the criteria defined by the Japanese Gastric Cancer Association. Surgical specimens were pathologically evaluated and graded according to the proportion of the tumor affected by degeneration or necrosis as follows: grade 0 , none of the tumor was affected; grade $1 \mathrm{a},<1 / 3$ of the tumor was affected; grade $1 b$, between $1 / 3$ and $2 / 3$ of the tumor was affected; grade $2,2 / 3$ of the tumor was affected; and grade 3 , there was no residual tumor. Any postoperative complications such as anastomotic leakage, intra-abdominal abscess or wound infection were evaluated. Postoperative complications were defined as those exceeding grade II in the Clavien-Dindo classification. Patient characteristics as well as peri- and postoperative outcomes are summarized in table 1 and table 2.

Case 1

A 53-year-old man had difficulty in swallowing. He underwent examination using a gastro fiberscope and was diagnosed with type 4 gastric cancer. A detailed examination of the patient was performed and included a CT scan, ${ }^{18} \mathrm{~F}$-fluorodeoxyglucose positron emission tomography-CT (FDG PET-CT) and a barium meal; the final diagnosis was c stage IV (cT4aN3M0) gastric cancer. Peritoneal dissemination was suspected using FDG PET-CT, and consequently staging laparoscopy was performed. Peritoneal dissemination was confirmed (fig. 1a, b). With regard to induction chemotherapy, since HER2 was positive (3+), trastuzumab (first cycle $8 \mathrm{mg} / \mathrm{kg}$, after two cycles $6 \mathrm{mg} / \mathrm{kg}$ on day 1) plus capecitabine $\left(2,000 \mathrm{mg} / \mathrm{m}^{2}\right.$ on days $\left.1-14\right)$ combined with cisplatin $\left(80 \mathrm{mg} / \mathrm{m}^{2}\right.$ on day 1$)$ was administered. After chemotherapy, we judged that the original tumor was resectable and that dissemination had disappeared on imaging, and we performed staging laparoscopy for a second time. Since peritoneal dissemination was not found during the second staging laparoscopy (fig. 1c, d), we carried out TLTG [6]. The patient commenced meal intake on the third day after the operation and was discharged 10 days later without complications. Adjuvant 
Tsutsumi et al.: Laparoscopic Gastrectomy for Gastric Cancer with Peritoneal Dissemination after Induction Chemotherapy

chemotherapy was initiated 21 days after surgery. To date, we have followed up this patient for 16 months after surgery and there has been no cancer recurrence.

Case 2

A 71-year-old man who suffered from abdominal pain was admitted to our hospital. Detailed examination included a CT scan, FDG PET-CT and a barium meal; the subsequent diagnosis was gastric cancer. We had planned to carry out TLTG, but when we inspected the abdominal cavity, ascites and peritoneal dissemination were evident. The patient was finally diagnosed with s stage IV (sT4aN3M0H0P1CY1) gastric cancer. 7 days after laparoscopic examination, S-1 (oral; $100 \mathrm{mg} /$ day on days $1-21)$ combined with cisplatin $\left(60 \mathrm{mg} / \mathrm{m}^{2}\right.$ on day 8) were administered in three cycles as induction chemotherapy. After chemotherapy we performed a laparoscopic examination. No pathological dissemination was found during the operation. Thus, we judged that the cancer was resectable and undertook TLTG [6, 7]. The patient began food intake on the third day after surgery and was discharged without complications 10 days later. Adjuvant chemotherapy was begun 36 days after the operation. To date, we have followed up this patient for 14 months after surgery and cancer has not recurred.

Case 3

A 65-year-old man had stomach discomfort. He underwent a gastro fiberscope examination and was diagnosed with type 4 gastric cancer. He was admitted to our hospital and a detailed examination was carried out. The diagnosis was stage IV (T4aN0M0H0P1) gastric cancer. FDG PET-CT examination indicated possible peritoneal dissemination because of the presence of ascites. Staging laparoscopy revealed pathological peritoneal dissemination. S-1 (oral; $80 \mathrm{mg} / \mathrm{m}^{2}$ on days $\left.1-21\right)$ combined with cisplatin $\left(60 \mathrm{mg} / \mathrm{m}^{2}\right.$ on day 8) was administered in two cycles as induction chemotherapy. After chemotherapy, dissemination had disappeared on imaging and we decided that the original tumor was resectable. We performed staging laparoscopy to confirm that the tumor was resectable and TLTG was carried out continuously [6]. The patient started to eat on the third day after the operation and was discharged without complications 10 days later. Adjuvant chemotherapy commenced 21 days after the operation. To date, we have followed up this patient for 10 months after surgery with no evidence of cancer recurrence.

\section{Discussion}

In recent years, preoperative chemotherapy has become an established treatment for advanced gastric cancer in many facilities and has been reported to improve clinical response and long-term survival $[8,9]$. Indeed, in patients with localized gastric or gastroesophageal adenocarcinoma, preoperative chemotherapy combined with postoperative chemotherapy has significantly prolonged survival as compared with surgery alone [10]; a beneficial therapeutic effect has also been reported for gastric cancer with peritoneal dissemination $[2,3]$. Thus, more recent advances in chemotherapy have increased the potential for surgery even in cases of peritoneal dissemination.

Laparoscopic surgery has become commonplace as a treatment for gastric cancer. Some studies have reported that laparoscopic surgery has a number of advantages over open gastrectomy [11, 12]. First, the surgery is much less invasive and recovery time is shorter. Second, with a laparoscopic examination wasteful surgery can be avoided. Third, since some studies have found that there is a relationship between cancer and inflammation [13], it is 
Tsutsumi et al.: Laparoscopic Gastrectomy for Gastric Cancer with Peritoneal Dissemination after Induction Chemotherapy

believed that the effectiveness of laparoscopic surgery in the treatment of cancer can be improved if minor inflammation is present. However, some disadvantages have been reported regarding laparoscopic surgery for gastric cancer. The procedure is difficult and washing of the abdominal cavity can be less effective than is the case for open surgery. Although complications have been reported after gastrectomy because of a weakened immune system caused by chemotherapy [14], we did not experience any postoperative complications in our three cases.

Ajani et al. [15] reported in their study that the pathological complete response rate was $20 \%$ and the partial response rate was $15 \%$. In our study, postoperative pathological examination carried out to investigate the efficacy of chemotherapy revealed a grade 2 pathological response in two out of the three cases. In one case, there was lymph node metastasis (N3) before chemotherapy, but there were no malignant findings (N0) after surgery. Induction chemotherapy was effective not only for the tumor, but also for lymph node metastases.

There have been a number of studies where surgery was performed after chemotherapy for the treatment of gastric cancer with peritoneal dissemination [4]. Yamamoto et al. [4] reported that the median survival time of patients in the group that underwent surgery after chemotherapy was significantly higher than that in the group treated with chemotherapy alone. It is unknown whether surgical resection contributes to improved prognosis in such cases; careful follow-up of these cases will be necessary in the future. In our study, the three patients have been followed up for up to 16 months after surgery, and all have exhibited recurrence-free survival.

There are some advantages in performing laparoscopic surgery after induction chemotherapy for cases where there has been no adaptation of the surgery for peritoneal dissemination. First, we can expect a reduction in the size of the tumor as a result of chemotherapy; thus, it is easier to perform surgery in cases who have undergone chemotherapy than in cases who have not undergone chemotherapy. Second, since laparoscopic surgery is less invasive, the physical status of the patient is not diminished and chemotherapy can be administered before and immediately after surgery. Third, since surgery can reduce the volume of the tumor more effectively than continued chemotherapy alone, it is believed that there is potential for improved prognosis. For these reasons, we should provide treatment on the assumption that laparoscopic surgery will be performed after induction chemotherapy, even in cases of peritoneal dissemination.

In conclusion, since laparoscopic gastrectomy undertaken after induction chemotherapy was found to be effective and safe, it could be used to achieve improved treatment outcomes. In the future, it has the potential to become one of the important treatment strategies for advanced gastric cancer with peritoneal dissemination.

\section{Disclosure Statement}

The authors declare that they have no conflicts of interest to disclose. 


\begin{tabular}{l|l}
\hline \multicolumn{2}{l}{ Case Rep Gastroenterol 2013;7:516-521 } \\
\hline DOI: 10.1159/000357591 & $\begin{array}{l}\text { C 2013 S. Karger AG, Basel } \\
\text { www.karger.com/crg }\end{array}$ \\
\hline
\end{tabular}

Tsutsumi et al.: Laparoscopic Gastrectomy for Gastric Cancer with Peritoneal Dissemination after Induction Chemotherapy

\section{References}

1 Jemal A, Siegel R, Ward E, Hao Y, Xu J, Murray T, Thun MJ: Cancer statistics, 2008. CA Cancer J Clin 2008;58:71-96.

-2 Fujiwara Y, Takiguchi S, Nakajima K, Miyata H, Yamasaki M, Kurokawa Y, Okada K, Mori M, Doki Y: Neoadjuvant intraperitoneal and systemic chemotherapy for gastric cancer patients with peritoneal dissemination. Ann Surg Oncol 2011;18:3726-3731.

-3 Yonemura Y, Elnemr A, Endou Y, Ishibashi H, Mizumoto A, Miura M, Li Y: Effects of neoadjuvant intraperitoneal/systemic chemotherapy (bidirectional chemotherapy) for the treatment of patients with peritoneal metastasis from gastric cancer. Int J Surg Oncol 2012;2012:148420.

-4 Yamamoto M, Matsuyama A, Yoshinaga K, Iwasa T, Tsutsui S, Ishida T: Preliminary trial of surgery after chemotherapy for advanced gastric cancer with peritoneal dissemination. Oncol Lett 2012;3:662-666.

$\checkmark 5$ Dikken JL, van de Velde CJ, Gonen M, Verheij M, Brennan MF, Coit DG: The New American Joint Committee on Cancer/International Union Against Cancer staging system for adenocarcinoma of the stomach: increased complexity without clear improvement in predictive accuracy. Ann Surg Oncol 2012;19:2443-2451.

6 Ikeda T, Kawano H, Hisamatsu Y, Ando K, Saeki H, Oki E, Ohga T, Kakeji Y, Tsujitani S, Kohnoe S, Maehara Y: Progression from laparoscopic-assisted to totally laparoscopic distal gastrectomy: comparison of circular stapler (i-DST) and linear stapler (BBT) for intracorporeal anastomosis. Surg Endosc 2013;27:325-332.

7 Oki E, Sakaguchi Y, Ohgaki K, Saeki H, Chinen Y, Minami K, Sakamoto Y, Toh Y, Kusumoto T, Maehara Y: Feasibility of delta-shaped anastomoses in totally laparoscopic distal gastrectomy. Eur Surg Res 2011;47: 205-210.

-8 Ge L, Wang HJ, Yin D, Lei C, Zhu JF, Cai XH, Zhang GQ: Effectiveness of 5-flurouracil-based neoadjuvant chemotherapy in locally-advanced gastric/gastroesophageal cancer: a meta-analysis. World J Gastroenterol 2012;18:7384-7393.

-9 Iwasaki Y, Sasako M, Yamamoto S, Nakamura K, Sano T, Katai H, Tsujinaka T, Nashimoto A, Fukushima N, Tsuburaya A; Gastric Cancer Surgical Study Group of Japan Clinical Oncology Group: Phase II study of preoperative chemotherapy with S-1 and cisplatin followed by gastrectomy for clinically resectable type 4 and large type 3 gastric cancers (JCOG0210). J Surg Oncol 2013;107:741-745.

-10 Cunningham D, Allum WH, Stenning SP, Thompson JN, Van de Velde CJ, Nicolson M, Scarffe JH, Lofts FJ, Falk SJ, Iveson TJ, Smith DB, Langley RE, Verma M, Weeden S, Chua YJ, MAGIC Trial Participants: Perioperative chemotherapy versus surgery alone for resectable gastroesophageal cancer. N Engl J Med 2006;355:11-20.

11 Lee MS, Lee JH, Park do J, Lee HJ, Kim HH, Yang HK: Comparison of short- and long-term outcomes of laparoscopic-assisted total gastrectomy and open total gastrectomy in gastric cancer patients. Surg Endosc 2013;27:2598-2605.

12 Mamidanna R, Almoudaris AM, Bottle A, Aylin P, Faiz O, Hanna GB: National outcomes and uptake of laparoscopic gastrectomy for cancer in England. Surg Endosc 2013;27:3348-3358.

13 Elinav E, Nowarski R, Thaiss CA, Hu B, Jin C, Flavell RA: Inflammation-induced cancer: crosstalk between tumours, immune cells and microorganisms. Nat Rev Cancer 2013;13:759-771.

14 An JY, Kim KM, Kim YM, Cheong JH, Hyung WJ, Noh SH: Surgical complications in gastric cancer patients preoperatively treated with chemotherapy: their risk factors and clinical relevance. Ann Surg Oncol 2012;19:2452-2458.

15 Ajani JA, Mansfield PF, Crane CH, Wu TT, Lunagomez S, Lynch PM, Janjan N, Feig B, Faust J, Yao JC, Nivers R, Morris J, Pisters PW: Paclitaxel-based chemoradiotherapy in localized gastric carcinoma: degree of pathologic response and not clinical parameters dictated patient outcome. J Clin Oncol 2005;23:1237-1244.

Table 1. Patient characteristics and type of chemotherapy performed

\begin{tabular}{lllllllll}
\hline Case & Age & Sex & T & N & $\begin{array}{l}\text { HER2 } \\
\text { status }\end{array}$ & $\begin{array}{l}\text { Chemo- } \\
\text { therapy }\end{array}$ & $\begin{array}{l}\text { Number of } \\
\text { courses }\end{array}$ & $\begin{array}{l}\text { Pathological } \\
\text { response }\end{array}$ \\
\hline 1 & 53 & M & $4 \mathrm{a}$ & 3 & $3+$ & HXP & 5 & 2 \\
2 & 71 & M & $4 \mathrm{a}$ & 3 & 0 & SP & 2 & $1 \mathrm{~b}$ \\
3 & 65 & M & $4 \mathrm{a}$ & 0 & 0 & SP & 2 & 2 \\
\hline
\end{tabular}

HXP = Trastuzumab plus capecitabine combined with cisplatin; SP = S-1 combined with cisplatin. 


\begin{tabular}{l|l}
\hline Case Rep Gastroenterol 2013;7:516-521 \\
\hline DOI: $10.1159 / 000357591$ & $\begin{array}{l}\text { C 2013 S. Karger AG, Basel } \\
\text { www.karger.com/crg }\end{array}$ \\
\hline
\end{tabular}

Tsutsumi et al.: Laparoscopic Gastrectomy for Gastric Cancer with Peritoneal Dissemination after Induction Chemotherapy

Table 2. Peri- and postoperative patient outcomes

\begin{tabular}{llllll}
\hline Case & $\begin{array}{l}\text { Operation time, } \\
\text { min }\end{array}$ & $\begin{array}{l}\text { Bleeding, } \\
\mathrm{ml}\end{array}$ & Complications & $\begin{array}{l}\text { Postoperative stay, } \\
\text { days }\end{array}$ & $\begin{array}{l}\text { Stage pre/post } \\
\text { operation }\end{array}$ \\
\hline 1 & 322 & 140 & - & 13 & IV/IIA \\
2 & 369 & 50 & - & 10 & IV/IIIB \\
3 & 246 & 48 & - & 10 & IV/IIA \\
\hline
\end{tabular}

Tumor staging was based on the tumor, node, metastasis (TNM) classification system defined by the Union for International Cancer Control.
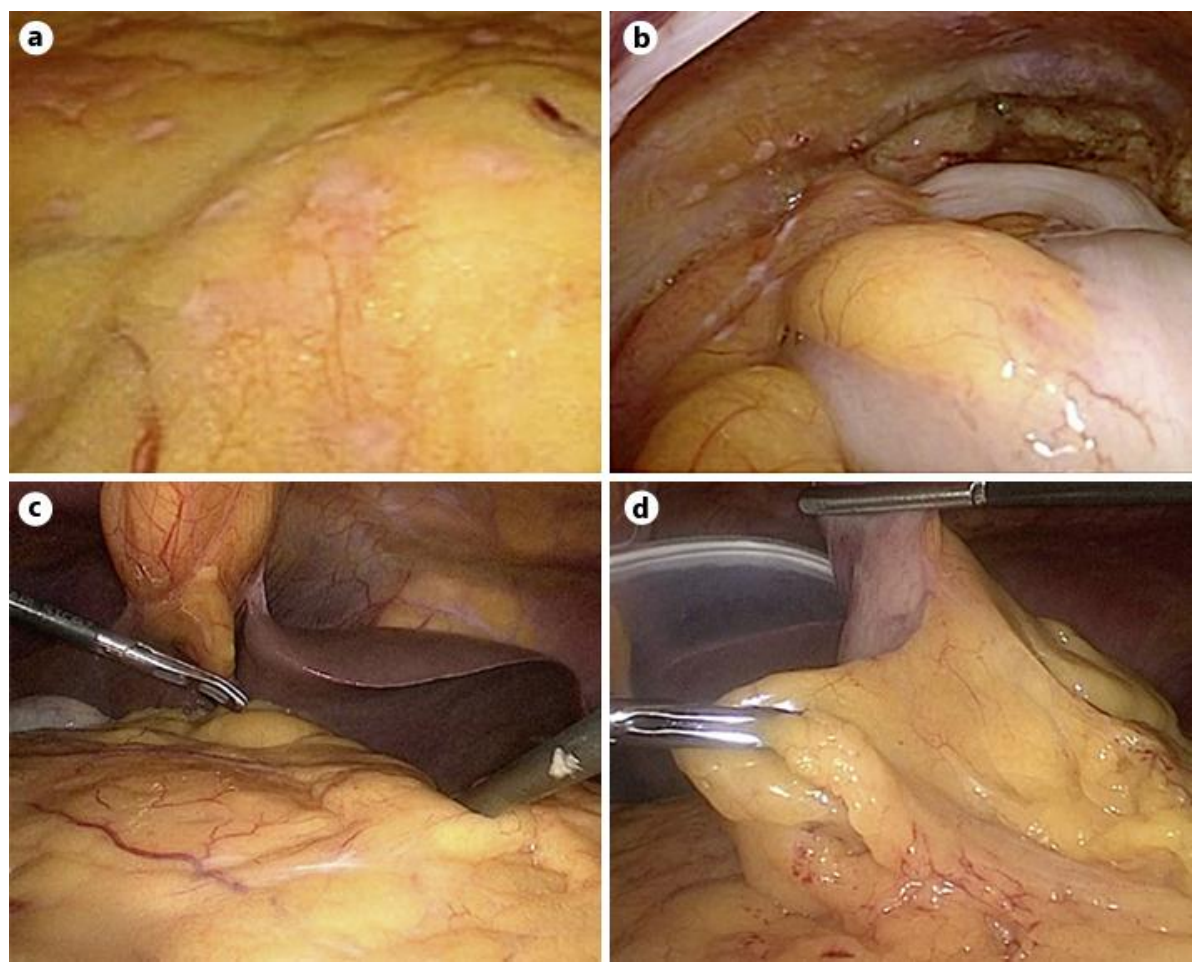

Fig. 1. a, b Photographs showing the presence of peritoneal dissemination during staging laparoscopy. c, $\mathbf{d}$ Photographs showing the disappearance of peritoneal dissemination after induction chemotherapy. 